\title{
Marcador microssatélite associado ao alelo $T y-1$ de resistência a Begomovirus em tomateiro
}

\author{
Danilo Gustavo Nogueira(1), Wilson Roberto Maluf(2), Douglas Willian Nogueira(1), Gabriel Mascarenhas Maciel(2), \\ Luciano Vilela Paiva ${ }^{(3)}$ e Antônia dos Reis Figueira ${ }^{(4)}$ \\ (1)Universidade Federal de Lavras (Ufla), Departamento de Biologia, Caixa Postal 3.037, CEP $37200-000$ Lavras, MG. \\ E-mail: asp.nogueira@yahoo.com.br, douglagen@yahoo.com.br (2)Ufla, Departamento de Agricultura. E-mail: wrmaluf@dag.ufla.br, \\ gabrielmascarenhasmaciel@yahoo.com.br ${ }^{(3)} \cup f l a$, Departamento de Química. E-mail: luciano@ufla.br ${ }^{(4)} U f l a$, Departamento de Fitopatologia. \\ E-mail: antonia@ufla.br
}

Resumo - O objetivo deste trabalho foi associar um marcador microssatélite ao alelo $T y-1$ de resistência a Begomovirus em tomateiro, e avaliar a eficiência desta associação na seleção de linhagens resistentes ao vírus. Os marcadores SSR-47 e SSR-48 foram testados em linhagens isogênicas contrastantes quanto à presença do alelo Ty-1 (LA-3473, LA-3474, LA-3475). O marcador SSR-47, por ter detectado polimorfismo nas linhagens, foi o único utilizado nas etapas subsequentes da pesquisa. Detectada a associação entre o SSR-47 e o alelo Ty-1, testou-se sua eficiência na seleção de genótipos avançados de tomateiro. Para confirmar a eficiência da seleção, foi realizada a avaliação fenotípica das plantas com padrões contrastantes de bandas para SSR-47, quanto à resistência a Begomovirus. Plantas que apresentaram banda única de $191 \mathrm{pb}$ foram resistentes ao Begomovirus, pelo teste de inoculação por enxertia; aquelas com banda única de 180 pb foram suscetíveis; e as plantas com bandas de 191 e 180 pb foram resistentes. A distância máxima entre o Ty-1 e o marcador SSR-47 foi de 2,7 cM. Este marcador foi efetivo em caracterizar genótipos portadores do alelo $T y-1$. As respostas das plantas à infecção pelo Begomovirus, induzida via enxertia, são consistentes com as reações previstas com o uso do marcador molecular SSR-47.

Termos para indexação: Geminiviridae, Lycopersicon esculentum, Solanum lycopersicum, QTL, seleção assistida por marcadores.

\section{Microsatelite marker associated with the Ty-1 allele for resistance to Begomovirus in tomato}

\begin{abstract}
The objective of this work was to associate a microsatellite marker with the $T y$ - 1 allele that controls resistance to Begomovirus in tomatoes, and to assess the eficiency of this association in the selection of virus-resistant lines. Microsatellite markers SSR-47 and SSR-48 were tested in near isogenic tomato lines (LA-3473, LA-3474, LA-3475) with contrasting genotypes for the $T y-1$ allele. The marker SSR-47 detected polymorphism in the lines, and was the only one used in the subsequent research phases. An association between the SSR-47 marker and the Ty-1 locus was detected, and its efficiency for selection of begomovirus-resistant genotypes in tomato was assessed. To confirm the selection efficiency, plants with contrasting banding patterns for the SSR-47 marker were tested for their reaction to Begomovirus. All plants with a single 191-bp band were resistant to Begomovirus, through inoculation test by grafting. Plants with a single 180-bp band were susceptible, and plants with both $191 \mathrm{bp}$ and $180 \mathrm{bp}$ bands were resistant. The maximum distance between $T y-1$ and the SSR-47 marker was $2.7 \mathrm{cM}$. This marker was efficient to identify genotypes bearing the $T y-1$ allele. Plant responses to infection by Begomovirus inoculated through grafting were consistent with reactions predicted with the use of the SSR-47 marker.
\end{abstract}

Index terms: Geminiviridae, Lycopersicon esculentum, Solanum lycopersicum, QTL, marker assisted selection.

\section{Introdução}

As doenças conhecidas como geminiviroses causam perdas significativas à cultura do tomateiro, nas principais regiões do mundo onde essa solanácea é cultivada(Faria etal., 2000; Moriones \& Navas-Castillo,
2000). Entre os geminivírus (família Geminiviridae), o gênero Begomovirus, que infecta o tomate (Solanum lycopersicum L. syn. Lycopersicon esculentum Mill.) é transmitido, principalmente, pelas moscas-brancas do gênero Bemisia. As espécies de Begomovirus podem apresentar genoma bipartido ou monopartido. 
No Brasil, diversos surtos de geminiviroses foram observados em tomateiro, principalmente, após a introdução de Bemisia argentifolii Bellows \& Perring e, atualmente, há diversas espécies de Begomovirus que infectam essa cultura (Castillo-Urquiza et al., 2008; Fauquet et al., 2008). Os principais sintomas causados são enrolamento da folha, epinastia, mosaico-dourado, rugoses, cloroses nervais, cloroses internervais, mosqueado e atrofia, que causam redução da floração, paralisação no crescimento e consequente perda da produção, principalmente se a infecção das plantas ocorrer nos estádios iniciais de desenvolvimento (Zhou et al., 2008).

Em campo, a disseminação do vírus é, em geral, controlada por meio do manejo químico da mosca-branca; entretanto, esse procedimento não é totalmente eficaz, em razão do aparecimento de populações resistentes a inseticidas (Gerling, 1990) e pelo fato de a doença ser diagnosticada em estádios avançados, na maioria das vezes (Silva et al., 2000). Dessa forma, um dos métodos mais promissores para o controle da doença é o uso de cultivares resistentes (Matos et al., 2003). Poucas fontes de resistência a geminivírus vêm sendo utilizadas no desenvolvimento de cultivares comerciais e, dessas, a mais comum é a conferida pelo alelo $T y-1$, proveniente da espécie selvagem S. chilense Dunal (Santana et al., 2001; Maruthi et al., 2003). Na Europa, acessos tolerantes a Begomovirus com genoma monopartido foram também tolerantes a alguns isolados com genoma bipartido (Santana et al., 2001; Matos et al., 2003), em consequência da introgressão do alelo $T y$-1. Estudos recentes, realizados no Brasil, mostraram que o loco Ty-1 confere reação de tolerância a distintas espécies de Begomovirus bipartidos (Boiteux et al., 2007).

As poucas cultivares resistentes disponíveis no mercado resultaram de melhoramento genético convencional. Em geral, para isso, são realizados vários cruzamentos e posterior fenotipagem dos indivíduos obtidos por meio de inoculações. Para diminuir essas dificuldades em fenotipar e selecionar os indivíduos desejados, principalmente quanto à resistência às doenças de natureza virótica (Menezes et al., 2004; El Mehrach et al., 2005), a identificação de marcadores moleculares ligados a alelos de resistência é um dos principais objetivos dos atuais programas de melhoramento para a cultura do tomateiro (Barone, 2009). A identificação de alelos de resistência a geminivírus, associados a marcadores moleculares, pode contribuir para estabelecer melhores estratégias de melhoramento e seleção de genótipos resistentes.

Vários são os tipos de marcadores moleculares associados a genes de resistência a doenças, entre eles destacam-se os microssatélites que possuem herança codominante (Ritschel et al., 2004). Mais de 40 alelos que conferem resistência a algumas das principais doenças do tomateiro estão associados a marcadores moleculares e estão disponíveis na literatura (Barone, 2009). Mais de 600 primers de microssatélite já foram descritos para o tomateiro - embora não mapeados, em sua maioria -, com grande potencial como candidatos a marcadores associados a genes que contêm alelos de resistência a doenças. Informações sobre esses marcadores estão disponíveis no endereço eletrônico do "International Solanaceae Genome Project" (Sol Genomics Network, 2010).

O alelo Ty-1, que confere resistência a Begomovirus, foi mapeado por Zamir et al. (1994) no cromossomo 6 , próximo à região do centrômero, intimamente ligado $(<1 \mathrm{cM})$ ao alelo $M i$, que confere resistência ao nematódeo-das-galhas (Meloidogyne spp.), porém em fase de repulsão. Portanto, linhagens cuja resistência a Begomovirus é conferida pelo alelo $T y$ - 1 são presumivelmente suscetíveis a nematóides $\left(\mathrm{Mi}^{+}\right)$.

O comprimento total do genoma do tomate foi estimado em aproximadamente $1.275 \mathrm{cM}$ (Livingstone et al., 1999) e, mais recentemente em $1.356 \mathrm{cM}$ (Zhang et al., 2002). Admitindo-se mais de 600 pares de primers de microssatélite, aleatoriamente distribuídos ao longo do genoma do tomateiro (Sol Genomics Network, 2010), ter-se-ia uma distância média entre esses marcadores estimada em aproximadamente 2,1 cM. Com base nesses números, é grande a possibilidade de se encontrarem marcadores microssatélites no cromossomo 6, associados ao alelo $T y$-1, principalmente porque trabalhos têm demonstrado que boa parte dos marcadores microssatélites estão associados à região centromérica do genoma do tomateiro, na qual $T y-1$ está localizado (Areshchenkova \& Ganal, 2002).

O objetivo deste trabalho foi associar um marcador microssatélite ao alelo $T y-1$, que confere resistência a Begomovirus em tomate, e avaliar a eficiência desta associação na seleção de linhagens resistentes ao vírus. 


\section{Material e Métodos}

Entre os mais de 600 pares de primers SSR (simple sequence repeat), desenvolvidos pela Universidade de Cornell (EUA) e disponíveis no Sol Genomics Network (2010), foram selecionados dois pares (SSR-47 e SSR-48) por estarem mapeados no cromossomo 6, próximo ao alelo $M i$ que, segundo Zamir et al. (1994), tem distância $<1 \mathrm{cM}$ do loco $T y-1$. Dos dois pares de primers escolhidos, o que detectou polimorfismo nas linhagens foi utilizado como possível marcador para Ty-1.

Para a verificação da existência de polimorfismo, SSR-47 e SSR-48 foram primeiramente testados em linhagens isogênicas contrastantes quanto à presença do alelo $T y$ - 1 . Foram utilizadas as seguintes linhagens, originárias do Charles M. Rick Tomato Genetics Stock Center, University of Califórnia - Davis: LA-3475, de constituição genotípica $T y-1^{+} / T y-1^{+}$, suscetível a geminivírus; LA-3473, de constituição genotípica Ty-1/ Ty-1, resistente a geminivírus e isogênica a LA-3475; e LA-3474, de constituição genotípica $T y-1^{+} / T y-1^{+}$, suscetível a geminivírus e isogênica a LA- 3475.

Para a verificação da existência ou não de polimorfismo entre os genótipos suscetíveis $\left(T y-1^{+} /\right.$ Ty- $1^{+}$) e resistentes (Ty-1/Ty-1) a Begomovirus, foram coletados folíolos de cada planta, colocados em envelopes de plástico devidamente identificados e acondicionados em caixa de isopor com gelo, e imediatamente levados ao Laboratório Central de Biologia Molecular, da Universidade Federal de Lavras, onde se realizou a extração do DNA.

O DNA foi extraído em microtubos de $1,5 \mathrm{~mL}$, a partir de $120 \mathrm{mg}$ de tecido foliar, conforme sugerido por Ferreira \& Grattapaglia (1998).

Para a reação em cadeia de polimerase (PCR), foi obtida uma mistura por amostra com: $2,5 \mu \mathrm{L}$ de tampão PCR 10X; 0,75 $\mu \mathrm{L} \mathrm{MgCl}_{2} 50 \mathrm{mmol} \mathrm{L}^{-1} ; 0,50$ $\mu \mathrm{L}$ de dNTP $10 \mathrm{mmol} \mathrm{L}^{-1} ; 1,25 \mu \mathrm{L}$ de cada iniciador ("forward" e "reverse") $10 \mathrm{mmol} \mathrm{L}^{-1} ; 0,25 \mu \mathrm{L}$ Taq DNA polimerase (Invitrogen Co.,Carlsbad, CA, EUA) 1 unidade; $1,0 \mu \mathrm{L}$ de DNA $20-50 \mathrm{ng} ; 17,5 \mu \mathrm{L}$ de água ultrapura autoclavada. A amplificação foi inicialmente conduzida por 5 min a $94^{\circ} \mathrm{C}$, seguido de 35 ciclos de $30 \mathrm{~s} \mathrm{a} 94^{\circ} \mathrm{C}, 45 \mathrm{~s} \mathrm{a} 45^{\circ} \mathrm{C}$, e $2 \min$ a $72^{\circ} \mathrm{C}$. A reação final de elongação foi de 5 min a $72^{\circ} \mathrm{C}$.

Para a realização da eletroforese, foram utilizados $11,5 \mu \mathrm{L}$ do produto da PCR de cada amostra, pipetados em 4,0 $\mu \mathrm{L}$ de corante azul de bromofenol $1 \mathrm{X}$.
A fixação dos fragmentos foi feita em gel de poliacrilamida a $15 \%$ e tampão TBE $1 \mathrm{X}$. A coloração foi feita com brometo de etídeo, e as bandas no gel foram visualizadas à luz ultravioleta a $260 \mathrm{~nm}$ e fotografadas.

Os primers utilizados foram os obtidos pela Sol Genomics Network (2010): para o SSR-47, o iniciador "forward" TCC TCA AGA AAT GAA GCT CTG A e o "reverse" CCT TGG AGA TAA CAA CCA CAA; e para o SSR-48, "forward" ATC TCC TTG GCC TCC TGT TT e o "reverse" GTC ATG GCC ACA TGA ATA CG. Dos dois marcadores escolhidos, apenas o SSR-47 apresentou polimorfismo e, por isso, foi utilizado nas etapas subsequentes do trabalho.

Detectada preliminarmente a associação entre o marcador SSR-47 e o alelo Ty-1, testou-se sua eficiência na seleção de genótipos avançados. Os padrões de bandas do marcador SSR-47, apresentados por plantas das populações BPX-373F, BPX-374F e BPX-375E, foram comparados com os das testemunhas LA-3473 (Ty-1/Ty-1, homozigoto resistente), LA-3474 (Ty-1 ${ }^{+}$ Ty $-1^{+}$, homozigoto suscetível), LA-3475 (Ty- $1^{+} /$ Ty- $1^{+}$, homozigoto suscetível) e TEX-143 (Ty-1+/Ty-1, heterozigoto resistente).

Novas linhagens de tomateiro foram obtidas a partir do cruzamento inicial da linhagem LA-3473 (suscetível a nematóide e resistente a geminivírus, $M i^{+} T y-1 /$ $\left.\mathrm{Mi}^{+} \mathrm{Ty}-1\right)$ com três diferentes linhagens de tomateiros homozigotas, para a resistência a nematóides e suscetibilidade a geminivírus (Mi Ty- $1^{+} / \mathrm{Mi} \mathrm{Ty}-1^{+}$). As linhagens resistentes a nematóides foram utilizadas como parentais recorrentes em três retrocruzamentos sucessivos, em cujas gerações segregantes sempre foram selecionadas plantas suscetíveis a nematóides $\left(\mathrm{Mi}^{+} / \mathrm{Mi}^{+}\right)$, presumivelmente resistentes a Begomovirus, embora essa resistência não houvesse sido testada. $\mathrm{Na}$ geração $\mathrm{F}_{4}$ do terceiro retrocruzamento, foi feita a seleção final, também quanto à suscetibilidade a nematóide $\left(\mathrm{Mi}^{+} / \mathrm{Mi}^{+}\right)$, tendo-se obtido plantas cujas populações foram designadas pelos códigos BPX-373F, BPX-374F e BPX-375E, respectivamente. A seleção quanto à suscetibilidade a nematóide $\left(\mathrm{Mi}^{+} / \mathrm{Mi}^{+}\right)$foi feita após inoculações de ovos de Meloidogyne spp. conforme Carvalho et al. (1999). A linhagem LA-3473, resistente a Begomovirus $\left(\mathrm{Mi}^{+} \mathrm{Ty}-1 / \mathrm{Mi}^{+} \mathrm{Ty}-1\right)$, foi utilizada em combinação a uma linhagem resistente a nematóide, reconhecidamente suscetível a geminivírus $\left(M i T y-1^{+} / M i T y-1^{+}\right)$, na obtenção do híbrido TEX-143, presumivelmente de genótipo $T y-1 / T y-1^{+}$, ou seja, 
resistente heterozigoto para $T y$-1. Essas plantas foram testadas com o marcador SSR-47 presumivelmente associado ao alelo $T y-1$.

Famílias $\mathrm{F}_{5} \mathrm{RC}_{3}$, resultantes da autofecundação de plantas BPX-373F, BPX-374F e BPX-375E, foram designadas respectivamente como BPX-373G, BPX-374G e BPX-375F, e testadas (20 plantas por família, com seleção direta e inoculação com vírus pelo processo de enxertia) quanto ao perfil de bandas gerado pelo marcador molecular SSR-47. Para isto, sementes BPX-373G, BPX-374G e BPX-375F foram semeadas em bandejas de isopor de 128 células, com substrato comercial Plantmax, junto com as testemunhas LA-3473 (homozigota resistente a Begomovirus), LA-3474 (homozigota suscetível), LA-3475 (homozigota suscetível) e TEX-143 (híbrido presumivelmente resistente, heterozigoto - Ty-1/ $T y-1^{+}$). Aos 28 dias após a semeadura, 20 plantas de cada família foram transplantadas para vasos de 1,5 L e infectadas pelo vírus, pelo processo de enxertia. Plantas de tomate da cultivar Santa Clara (suscetível a Begomovirus), foram utilizadas para a retirada de estacas com sintomas severos, coletadas da parte apical de plantas contaminadas com uma estirpe de Begomovirus. As estacas infectadas foram enxertadas em plantas assintomáticas a serem testadas. A inoculação por enxertia foi realizada após as plantas a serem testadas terem atingido o estádio fenológico ideal, de quatro a cinco folhas verdadeiras, ou 10 dias após o transplantio. Aos 40 dias após enxertia, as 20 plantas testadas de cada família foram avaliadas como suscetíveis ( $\mathrm{S}$, com presença de sintomas) ou resistentes ( $\mathrm{R}$, ausência de sintomas). A temperatura da casa de vegetação variou de 27 a $35^{\circ} \mathrm{C}$, e a umidade relativa do ar de 60 a $100 \%$, no período em que foi realizado o experimento.

A distância genética entre o marcador SSR-47 e o alelo $T y$ - 1 foi estimada com base na frequência de plantas recombinantes encontrada durante os retrocruzamentos que levaram à obtenção das populações BPX-373F, BPX-374F, e BPX-375E. Quando não se encontravam plantas recombinantes (suscetíveis a nematóides $-\mathrm{Mi}^{+}$/ $\mathrm{Mi}^{+}$, e com a banda SSR-47 correspondente à existente nas testemunhas $T y-1^{+} / 7 y-1^{+}$LA-3474 e LA-3475), estimava-se a distância máxima esperada entre esses alelos a $95 \%$ de probabilidade, por meio da expressão: $(1-c)^{\mathrm{n}} \geq 0,95$, em que né o número de retrocruzamentos efetuados, igual a 3 .

\section{Resultados e Discussão}

Bandas polimórficas foram observadas para o marcador molecular SSR-47, que apresentaram eficiência em distinguir entre linhagens LA-3473 - com plantas homozigotas resistentes (Ty-1/Ty-1) - e plantas homozigotas suscetíveis $\left(T y-1^{+} / T y-1^{+}\right)$de LA-3474 e LA-3475 (Figura 1). Plantas da linhagem LA-3473 mostraram uma banda única, de $191 \mathrm{pb}$, que caracteriza genótipos homozigotos resistentes (Ty-1/ Ty-1). Plantas das linhagens LA-3474 e LA-3475 mostraram uma banda única de $180 \mathrm{pb}$, que caracteriza genótipos homozigotos suscetíveis $\left(T y-1^{+} / T y-1^{+}\right)$. O marcador SSR-48 não apresentou polimorfismo entre os genótipos resistentes e suscetíveis.

As testemunhas LA-3473 (Ty-1/Ty-1, homozigoto resistente), LA-3474 (Ty- $1^{+} / T y-1^{+}$, homozigoto suscetível), LA-3475 (Ty- $1^{+} / T y-1^{+}$, homozigoto suscetível) e TEX-143 (Ty-1+/Ty-1, heterozigoto resistente) apresentaram, respectivamente, uma banda superior de $191 \mathrm{pb}$ em LA-3473, uma banda inferior de $180 \mathrm{pb}$ em LA-3474 e LA-3475, e as duas bandas (180 pb/191 pb) em TEX-143 (Tabela 1), o que confirma que o marcador SSR-47 é do tipo codominante - uma das vantagens do marcador microssatélite.

Todas as plantas das populações BPX-373F, BPX-374F e BPX-375E, quando testadas com o marcador SSR-47, apresentaram padrões de banda única de $191 \mathrm{pb}$, que caracteriza genótipos homozigotos resistentes (Ty-1/Ty-1), o mesmo padrão apresentado

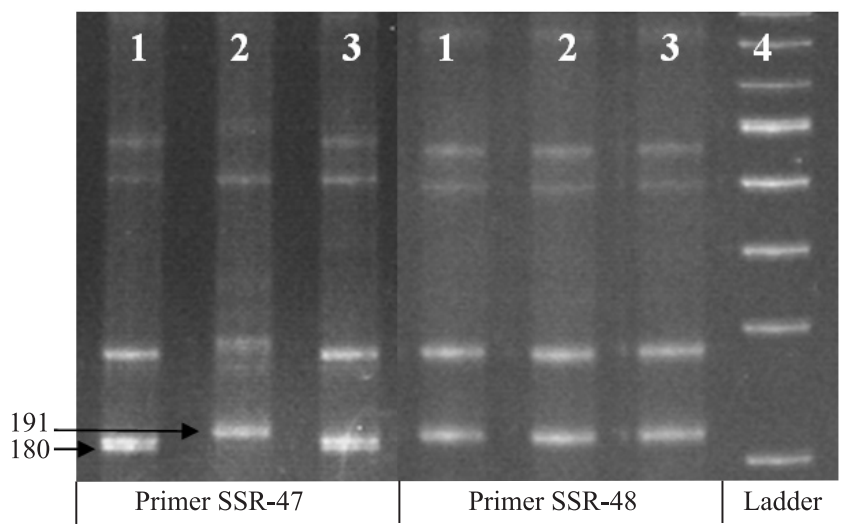

Figura 1. Padrão eletroforético de fragmentos de DNA amplificados para o marcador SSR-47 e SSR-48 em plantas de tomateiro; 1, LA- 3474, suscetível a Begomovirus (isogênico a LA-3475); 2, LA-3473, resistente a Begomovirus (isogênico a LA-3475); 3, LA-3475, suscetível a Begomovirus. 4, Ladder (100 pb) (Invitrogen Co., Carlsbad, CA, EUA). 
pela testemunha homozigota resistente LA-3473. Uma vez que durante o processo de sua obtenção foi utilizado apenas o critério de suscetibilidade a nematóides $\left(\mathrm{Mi}^{+} /\right.$ $M i^{+}$), fica evidente uma ligação gênica entre a reação a nematóides e o marcador SSR-47 utilizado.

Os locos Mi, Ty-1 e SSR-47 estão localizados muito próximos entre si (Zamir et al., 1994; Sol Genomics Network, 2010), portanto, era de se esperar uma alta frequência de associação entre os genótipos de plantas suscetíveis a nematóides $\left(\mathrm{Mi}^{+} / \mathrm{Mi}^{+}\right)$e a presença de

Tabela 1. Resultado do padrão eletroforético, com uso do marcador molecular SSR-47, em famílias avançadas (genótipos) de tomateiro.

\begin{tabular}{|c|c|c|c|}
\hline \multirow[t]{2}{*}{ Genótipo } & \multicolumn{3}{|c|}{ Padrão de bandas observadas } \\
\hline & $180 \mathrm{pb}$ & $180 / 191 \mathrm{pb}$ & $191 \mathrm{pb}$ \\
\hline LA-3473 (testemunha homozigota resistente) & - & - & + \\
\hline LA-3474 (testemunha homozigota suscetível) & + & - & - \\
\hline LA-3475 (testemunha homozigota suscetível) & + & - & - \\
\hline TEX-143 (heterozigoto resistente) & - & + & - \\
\hline BPX-373F-06-02-01 & - & - & + \\
\hline BPX-373F-06-03-02 & - & - & + \\
\hline BPX-373F-06-04-03 & - & - & + \\
\hline BPX-373F-06-06-01 & - & - & + \\
\hline BPX-373F-06-10-01 & - & - & + \\
\hline BPX-373F-06-10-02 & - & - & + \\
\hline BPX-373F-06-14-01 & - & - & + \\
\hline BPX-373F-06-16-01 & - & - & + \\
\hline BPX-373F-07-03-03 & - & - & + \\
\hline BPX-373F-07-04-01 & - & - & + \\
\hline BPX-373F-07-05-03 & - & - & + \\
\hline BPX-373F-07-09-03 & - & - & + \\
\hline BPX-374F-01-01-03 & - & - & + \\
\hline BPX-374F-01-02-03 & - & - & + \\
\hline BPX-374F-04-08-02 & - & - & + \\
\hline BPX-374F-04-12-01 & - & - & + \\
\hline BPX-374F-04-12-03 & - & - & + \\
\hline BPX-374F-05-07-01 & - & - & + \\
\hline BPX-374F-05-07-03 & - & - & + \\
\hline BPX-374F-06-02-02 & - & - & + \\
\hline BPX-375E-04-01-01 & - & - & + \\
\hline BPX-375E-04-01-02 & - & - & + \\
\hline BPX-375E-04-02-02 & - & - & + \\
\hline BPX-375E-04-02-03 & - & - & + \\
\hline BPX-375E-04-02-04 & - & - & + \\
\hline BPX-375E-04-03-02 & - & - & + \\
\hline BPX-375E-04-03-03 & - & - & + \\
\hline BPX-375E-04-08-01 & - & - & + \\
\hline BPX-375E-04-08-03 & - & - & + \\
\hline BPX-375E-04-08-04 & - & - & + \\
\hline BPX-375E-04-11-04 & - & - & + \\
\hline BPX-375E-04-12-02 & - & - & + \\
\hline BPX-375E-04-12-03 & - & - & + \\
\hline ВРX-375E-04-12-04 & - & - & + \\
\hline
\end{tabular}

banda única, de 191 pb. Dessa forma, não foi detectada nenhuma planta recombinante, isto é, suscetível a nematóides $\left(\mathrm{Mi}^{+} / \mathrm{Mi}^{+}\right)$e possuidora de banda, de 180 pb. Essa ausência de recombinantes, mesmo após os três retrocruzamentos utilizados para a obtenção das populações BPX-373F, BPX-374F e BPX-375E, permitiu estimar a distância genética, entre $M i$ e o marcador SSR-47, em um valor máximo de c, 1,7 cM, a $95 \%$ de probabilidade, valor obtido pela expressão $(1-\mathrm{c})^{3} \geq 0,95$.

A distância de 1,7 cM está próxima da encontrada no mapa do tomateiro $(1,0 \mathrm{cM})$, em que o alelo $M i$ está mapeado a 5,5 cM, e o marcador SSR-47 a $6,5 \mathrm{cM}$ da extremidade do cromossomo 6 (Sol Genomics Network, 2010). Uma vez que a distância entre $M i$ e Ty-1 é provavelmente inferior a $1 \mathrm{cM}$ (Zamir et al., 1994), pode-se estimar a distância máxima esperada entre $T y-1$ e o marcador SSR-47 como de $(1+1,7)=$ 2,7 cM, com a distância entre $M i$ e o marcador SSR-47 de 1,7 cM. Quando se considera a distância de $1 \mathrm{cM}$, obtida pelo mapa do Sol Genomics Network (2010), tem-se $(1+1)=2,0 \mathrm{cM}$ de distância, resultado obtido na hipótese de a sequência linear dos locos ser $T y-1 \rightarrow M i$ $\rightarrow$ SSR-47. Na hipótese de a sequência linear dos locos ser $M i \rightarrow T y-1 \rightarrow$ SSR-47, a distância estimada entre Ty-1 e o marcador SSR-47 seria de aproximadamente $(1,7-1)=0,7 \mathrm{cM}$, com a distância calculada, e de $(1-1)=0,0 \mathrm{cM}$, quando se considera a distância obtida pelo mapa. No presente ensaio, não foi possível distinguir qual das hipóteses de sequência linear dos locos é a verdadeira, mas, de qualquer modo, a distância máxima de apenas $2,7 \mathrm{cM}$ é bastante próxima da estimada pelo mapa do Sol Genomics Network (2010), o que indica a utilidade do marcador SSR-47 para a seleção assistida de plantas resistentes a Begomovirus.

Plantas $\mathrm{F}_{4} \mathrm{RC}_{3}$ das populações BPX-373F, BPX-374F e BPX-375E, previamente identificadas como portadoras da banda de $191 \mathrm{pb}$, normalmente associada ao genótipo $T y-1 / T y-1$, tiveram suas respectivas famílias $\mathrm{F}_{5} \mathrm{RC}_{3} \mathrm{BPX}-373 \mathrm{G}, \mathrm{BPX}-374 \mathrm{G}$ e BPX-375F (20 plantas por família) testadas fenotipicamente quanto à resistência ao vírus, pelo processo de inoculação por enxertia e, genotipicamente, com o marcador SSR-47.

As famílias obtidas - BPX-373G-06-02-01, BPX-373G-06-10-01, BPX-373G-07-03-03, BPX-374G-01-01-03, BPX-374G-01-02-03, BPX-374G-04-08-02, BPX-374G-04-12-01, BPX-375F-04-01-02, BPX-375F-04-08-04-, bem como a testemunha resistente LA-3473 (Tabela 2), 
mostraram reação de resistência ao vírus, pois as brotações novas não apresentaram nenhum sintoma característico, o que as caracterizou como resistentes a Begomovirus. Análise feita com o marcador SSR-47, em todas as plantas de cada família, revelou apenas a presença da banda de $191 \mathrm{pb}$, que caracteriza famílias homozigotas resistentes $(T y-1 / T y-1)$ (Tabela 2 e Figura 2).

Todas as plantas do híbrido TEX-143 apresentaram sintomas atenuados da doença, logo após o processo de inoculação, que diminuíram em razão do surgimento de brotações novas mais distantes do ponto de enxertia, e por isso foram classificadas como resistentes a Begomovirus. Essa ocorrência se explica pelo fato de o alelo $T y-1$ interferir na proteína viral responsável pela circulação do vírus na planta (Zamir et al., 1994), o que dificulta a disseminação sistêmica das partículas virais do enxerto para as brotações mais novas da planta. Boiteux et al. (2007) verificaram que genótipos heterozigotos $\left(T y-1 / T y-1^{+}\right)$e homozigotos suscetíveis $\left(T y-1^{+} / T y-1^{+}\right)$apresentaram 35 e $95 \%$ respectivamente de plantas com sintomas de infecção por Begomovirus, após terem sido submetidos a condições de inóculo natural, em elevada densidade populacional de mosca-branca virulífera. Esses resultados são indicativos de que o alelo $T y-1$ é efetivo mesmo em heterozigose. No entanto, os autores não avaliaram genótipos homozigotos resistentes (Ty-1/Ty-1).

As reações fenotípicas de resistência e suscetibilidade a Begomovirus mostram perfeita concordância com

Tabela 2. Descrição dos tratamentos, reação fenotípica e resultado do padrão eletroforético, com uso do marcador molecular SSR-47.

\begin{tabular}{|c|c|c|c|c|c|c|}
\hline \multirow[t]{2}{*}{ Genótipo } & \multirow[t]{2}{*}{ Número de plantas avaliadas } & \multicolumn{2}{|c|}{ Reação $^{(1)}$} & \multicolumn{3}{|c|}{ Padrão de bandas observadas ${ }^{(2)}$} \\
\hline & & $\mathrm{S}$ & $\mathrm{R}$ & $180 \mathrm{pb}$ & $180 / 191 \mathrm{pb}$ & $191 \mathrm{pb}$ \\
\hline LA-3473 & 20 & 0 & 20 & - & - & $+(20)$ \\
\hline LA-3474 & 20 & 20 & 0 & $+(20)$ & - & - \\
\hline LA-3475 & 20 & 20 & 0 & $+(20)$ & - & - \\
\hline TEX-143 & 20 & 0 & 20 & - & $+(20)$ & - \\
\hline BPX-373G-06-02-01 & 20 & 0 & 20 & - & - & $+(20)$ \\
\hline BPX-373G-06-10-01 & 20 & 0 & 20 & - & - & $+(20)$ \\
\hline BPX-373G-07-03-03 & 20 & 0 & 20 & - & - & $+(20)$ \\
\hline BPX-374G-01-01-03 & 20 & 0 & 20 & - & - & $+(20)$ \\
\hline BPX-374G-01-02-03 & 20 & 0 & 20 & - & - & $+(20)$ \\
\hline BPX-374G-04-08-02 & 20 & 0 & 20 & - & - & $+(20)$ \\
\hline BPX-374G-04-12-01 & 20 & 0 & 20 & - & - & $+(20)$ \\
\hline BPX-375F-04-01-02 & 20 & 0 & 20 & - & - & $+(20)$ \\
\hline BPX-375F-04-08-04 & 20 & 0 & 20 & - & - & $+(20)$ \\
\hline
\end{tabular}

${ }^{(1)}$ S, Suscetível; R, Resistente; (2)Número entre parênteses indica número de plantas avaliadas que apresentaram a banda indicada.

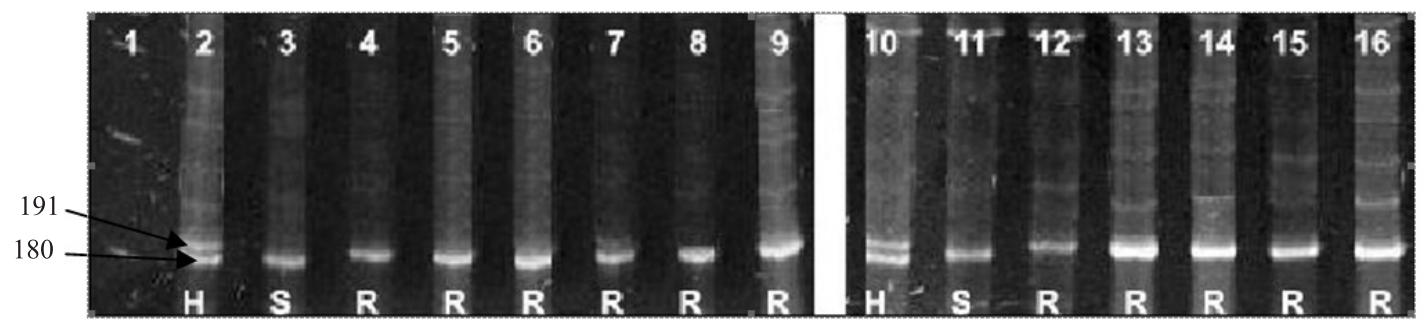

Figura 2. Padrão eletroforético de fragmentos de DNA, amplificados para o marcador SSR-47 em plantas de tomateiro; 1, Ladder (100 pb) (Invitrogen Co., Carlsbad, CA, EUA); 2, TEX-143; 3, LA-3474; 4, LA-3473; 5, BPX-373G-06-02-01; 6, BPX-373G-06-10-01; 7, BPX-373G-07-03-03; 8, BPX-374G-01-01-03; 9, BPX-374G-01-02-03; 10, TEX-143; 11, LA-3475; 12, LA-3473; 13, BPX-374G-04-08-02; 14, BPX-374G-04-12-01; 15, BPX-375F-04-01-02; 16, BPX-375F-04-08-04. $\mathrm{H}$, heterozigoto; $\mathrm{S}$, homozigoto suscetível; $\mathrm{R}$, homozigoto resistente. 
os resultados obtidos com o genótipo indicado pelo marcador SSR-47 (Tabela 2 e Figura 2). Esse fato e a distância bastante próxima estimada entre os locos $T y-1$ e SSR-47 permitem concluir que a seleção de plantas resistentes a Begomovirus, com base no marcador SSR-47, pode substituir com boa margem de segurança a seleção de plantas resistentes com base na avaliação fenotípica.

\section{Conclusões}

1. O marcador SSR-47 está associado ao alelo $T y-1$, à distância estimada de no máximo $2,7 \mathrm{cM}$.

2. O marcador molecular SSR-47 apresenta utilidade para a caracterização de genótipos de tomateiro quanto à presença do alelo $T y-1$ de resistência a Begomovirus.

3. As famílias BPX-373G-06-02-01, BPX-373G-06-10-01, BPX-373G-07-03-03, BPX-374G-01-01-03, BPX-374G-01-02-03, BPX-374G-04-08-02, BPX-374G-04-12-01, BPX-375F-04-01-02, BPX-375F-04-08-04, a testemunha LA-3473 e o híbrido TEX-143 apresentam resistência a Begomovirus.

\section{Agradecimentos}

À Fundação de Amparo à Pesquisa do Estado de Minas Gerais; ao Conselho Nacional de Desenvolvimento Científico e Tecnológico; à Coordenação de Aperfeiçoamento de Pessoal de Nível Superior; à Universidade Federal de Lavras (Ufla); à Fundação de Apoio ao Ensino, Pesquisa e Extensão; à Fundação de Desenvolvimento Científico e Cultural; à empresa HortiAgro Sementes S.A.; ao Laboratório Central de Biologia Molecular/Ufla; e ao Laboratório de Virologia Molecular/Ufla.

\section{Referências}

ARESHCHENKOVA, T.; GANAL, M.W. Comparative analysis of polymorphism and chromosomal location of tomato microssatellite markers isolated from different sources. Theoretical and Applied Genetics, v.104, p.229-235, 2002.

BARONE, A. Molecular marker-assisted selection for resistance to pathogens in tomato. Available at: $<$ http://www.fao.org/biotech/ docs/Barone.pdf>. Accessed on: 15 July 2009.

BOITEUX, L.S.; OLIVEIRA, V.R.; SILVA, C.H.; MAKISHIMA, N.; INOUE-NAGATA, A.K.; FONSECA, M.E. de N.; GIORDANO, L. de B. Reaction of tomato hybrids carrying the $T y-1$ locus to Brazilian bipartite Begomovirus species. Horticultura Brasileira, v.25, p.20-23, 2007.
CARVALHO, J.W.A.; MALUF, W.R.; FIGUEIRA, A.R.; GOMES, L.A.A. Obtenção de linhagens de tomateiro de crescimento determinado com resistência múltipla a nematóides de galhas e a tospovírus. Ciência e Agrotecnologia, v.23, p.593-607, 1999.

CASTILLO-URQUIZA, G.P.; BESERRA JUNIOR, J.E.A.; BRUCKNER, F.P.; LIMA A.T.M.; VARSANI, A.; ALFENAS-ZERBINI, P.; ZERBINI, F.M. Six novel begomoviruses infecting tomato and associated weeds in Southeastern Brazil. Archives of Virology, v.153, p.1985-1989, 2008.

EL MEHRACH, K.; GHARSALLAH CHOUCHANE, S.; MEJIA, L.; WILLIAMSON, V.M.; VIDAVSKI, F.; HATIMI, A.; SALUS, M.S.; MARTIN, C.T.; MAXWELL, D.P. PCR-based methods for tagging the $\mathrm{Mi}-1$ locus for resistance to root-knot nematode in begomovirus-resistant tomato germoplasm. Acta Horticulturae, v.695, p.263-270, 2005.

FARIA, J.C.; BEZERRA, I.C.; ZERBINI, F.M.; RIBEIRO, S.G.; LIMA, M.F. Situação atual das geminiviroses no Brasil. Fitopatologia Brasileira, v.25, p.125-137, 2000.

FAUQUET, C.M.; BRIDDON, R.W.; BROWN, J.K.; MORIONES, E.; STANLEY, J.; ZERBINI, M.; ZHOU, X. Geminivirus strain demarcation and nomenclature. Archives of Virology, v.153, p.783-821, 2008.

FERREIRA, M.E.; GRATTAPAGLIA, D. Introdução ao uso de marcadores moleculares em análises genéticas. 3.ed. Brasília: Embrapa-Cenargen, 1998. 220p.

GERLING, D. Whiteflies: their bionomics, pest status and management. Andover: Intercept, 1990. 348p.

LIVINGSTONE, K.D.; LACKNEY, V.K.; BLAUTH, J.R.; WIJK, R. van; JAHN, M.K. Genome mapping in Capsicum and the evolution of genome structure in the Solanaceae. Genetics, v.152, p.1183-1202, 1999.

MARUTHI, M.N.; CZOSNECK, H.; VIAVSKI, F.; TARBA, S.-Y.; MILO, J.; LEVIATOT, S.; VENKATESH, H.M.; PADMAJA, A.S.; KULKARNI, R.S.; MUNIYAPPA, V. Comparison of resistance to Tomato leaf curl virus (India) and Tomato yellow leaf curl virus (Israel) among Lycopersicon wild species, breeding lines and hybrids. European Journal of Plant Pathology, v.109, p.1-11, 2003.

MATOS, E.S.; SIQUEIRA ,W.J.; LOURENÇÃO, A.L.; MELO A.M.T.; SAWAZAKI, H.E.; SOUZA-DIAS, J.A.C.; COLARICCIO, A. Resistência de genótipos de tomateiro a um isolado de geminivírus do cinturão verde de Campinas, São Paulo. Fitopatologia Brasileira, v.28, p.159-165, 2003.

MENEZES, C.B.; FIGUEIRA, A.R.; MALUF, W.R.; ZERBINI JÚNIOR, F.M.; NASCIMENTO, I.R.; NOGUEIRA, D.W.; STEVENS, M.R. Seleção assistida por marcadores em tomate para resistência a tospovírus (TSWV). Fitopatologia Brasileira, v.29, p.1-324, 2004. Suplemento.

MORIONES, E.; NAVAS-CASTILLO, J. Tomato yellow leaf curl virus, an emerging virus complex causing epidemics worldwide. Virus Research, v.71, p.123-134, 2000.

RITSCHEL, P.S.; LINS, T.C de L.; TRISTAN, R.L.; BUSO, G.S.C.; BUSO, J.A.; FERREIRA, M.E. Development of microsatellite markers from an enriched genomic library for genetic analysis of melon (Cucumis melo L.). Plant Biology, v.4, p.9-23, 2004. 
SANTANA, F.M.; RIBEIRO, S. da G.; MOITA, A.W.; MOREIRA JUNIOR, D.J.; GIORDANO, L. de B. Sources of resistance in Lycopersicon spp. to a bipartite whitefly-transmitted geminivirus from Brazil. Euphytica, v.122, p.45-51, 2001.

SILVA, J.B. da; GIORDANO, L. de B; FURUMOTO, O.; BOITEUX, L. da S.; FRANÇA, F.H.; VILLAS BÔAS, G.L.; CASTELO BRANCO, M.; MEDEIROS, M.A. de; MAROUELLI, W.; SILVA, W.L.C. e; LOPES, C.A., ÁVILA,A.C.; NASCIMENTO, W.M.; PEREIRAI, W. Cultivo do tomate para industrialização. Brasília: Embrapa Hortaliças, 2000. (Embapa Hortaliças. Sistema de produção, 3). Disponível em: <http://sistemasdeproducao. cnptia.embrapa.br/FontesHTML/Tomate/TomateIndustrial/ doencas_virus.htm>. Acesso em: 24 maio 2009.

SOL GENOMICS NETWORK. International Solanaceae Genome Project (SOL): systems approach to diversity and adaptation. Available at: $<$ http://solgenomics.net/solanaceae-project/index.pl $>$. Accessed on: 20 jun. 2010.
ZAMIR, D.; EKSTEIN-MICHELSON, I.; ZAKAY, Y.; NAVOT, N.; ZEIDAN, M.; SARFATTI, M.; ESHED, Y.; HAREL, E.; PLEBAN, T.; VAN-OSS, H.; KEDAR, N.; RABINOWITCH, H.D.; CZOSNEK, H. Mapping and introgression of tomato yellow leaf curl virus tolerance gene, $T y-1$. Theoretical and Applied Genetics, v.88, p.141-146, 1994.

ZHANG, L.P.; KHAN, A.; NINO-LIU, D.; FOOLAD, M.R. A molecular linkage map of tomato displaying chromosomal locations of resistance gene analogs based on a Lycopersicon esculentum x Lycopersicon hirsutum cross. Genome, v.45, p.133-146, 2002.

ZHOU,Y.C.; NOUSSOUROU, M.; KON, T.; ROJAS, M.R.; JIANG, H.; CHEN, L.F.; GAMBY, K.; FOSTER, R.; GILBERTSON, R.L. Evidence of local evolution of tomato-infecting Begomovirus species in West Africa: characterization of Tomato leaf curl Mali virus and Tomato yellow leaf crumple virus from Mali. Archives of Virology, v.153, p.693-703, 2008.

Recebido em 14 de setembro de 2010 e aprovado em 20 de abril de 2011 